\title{
Dataset for Mosquitoes (Diptera: Culicidae) from Cross Key, Monroe County, Florida, USA
}

\author{
Lawrence J. Hribar $\ddagger$
}

‡ Florida Keys Mosquito Control District, Florida, United States of America

Corresponding author: Lawrence J. Hribar (Ihribar@keysmosquito.org)

\section{Abstract}

\section{Background}

The Florida Keys Mosquito Control District deploys dry ice-baited light traps to monitor mosquito populations throughout the Florida Keys. Cross Key is an island directly north of Key Largo and via bridges it serves as a link between Key Largo and mainland Florida.

\section{New information}

This paper describes a data set compiled from trap collections on Cross Key, Florida, between September 23, 2002 and March 1, 2016.

\section{Keywords}

Diptera, Culicidae, seasonal abundance, Cross Key, mosquito trap 


\section{Introduction}

The Florida Keys Mosquito Control District uses dry ice-baited light traps to conduct adult mosquito surveillance (Hribar 2002). Traps are deployed weekly except for interruptions due to storms, illness, or problematic situations. Each trap is provisioned with approximately 2 pounds of dry ice, deployed in the late afternoon, and retrieved the following morning. Traps are hung from the same tree limb every week unless trees have been uprooted due to storrms or cut down. Mosquitoes are treansported to the laboratory, killed by freezing, and identified to species.

\section{General description}

Purpose: These data were collected to document the species composition, relative abundance, and seasonal distribution of mosquitoes (Diptera: Culicidae) on Cross Key.

\section{Sampling methods}

Study extent: The data presented herein were collected between September 2002 and March 2016 on Cross Key, an island north of Key Largo and south of mainland Florida. Data collection was attempted weekly although due to storms, illness, and vacation some weeks were missed.

Sampling description: Battery-powered light traps (American Biophysics Company, Clarke, John Hock) were provisioned with approximately two pounds of dry ice and hung from the same tree limb once weekly. Traps were set in the late afternoon and retreived the following morning. Trap catch was taken to the laboratory, frozen, and all mosquitoes separated, identified with the aid of Darsie and Morris 2003, and counted. Nonmosquito bycatch was examined ocassionally and reported elsewhere (Hribar 2020). Mosquito data were recorded in spreadsheets. Dates when no mosquitoes were collected are designated "No Mosquitoes" in the spreadsheet.

Red mangrove (Rhizophora mangle L.), black mangrove (Avicennia germinans L.), and buttonwood (Conocarpus erecta L.) comprise the majority of the flora at the site, with other typical marsh and hammock species present (Hribar 2002). Aedes taeniorhynchus (Wiedemann) and Anopheles atropos Dyar \& Knab are the most commonly collected moquitoes at this site (DeMay and Hribar 2008).

\section{Geographic coverage}

Description: The island of Cross Key in Monroe County, Florida, United States.

Coordinates: $25^{\circ} 11^{\prime} 17.51^{\prime \prime}$ and 25 $5^{\circ} 11^{\prime} 17.51^{\prime \prime}$ Latitude; $80^{\circ} 23^{\prime} 28.48^{\prime \prime}$ and $80^{\circ} 23^{\prime} 28.48^{\prime \prime}$ Longitude. 


\section{Usage licence}

Usage licence: Creative Commons Public Domain Waiver (CC-Zero)

\section{Data resources}

Data package title: Excel

\section{Number of data sets: 1}

Data set name: Cross_Key

Description: Excel 2013 spreadsheet containing number of male and female mosquitoes collected per species with dates of deployment and retrieval of traps.

\begin{tabular}{|l|l|}
\hline Column label & Column description \\
\hline Species & Species Identification \\
\hline Male & Number of male specimens collected \\
\hline Female & Number of female specimens collected \\
\hline trap_place & Date trap deployed \\
\hline trap_retri & Date trap retrieved \\
\hline
\end{tabular}

\section{Additional information}

The size of the dataset is $68.37 \mathrm{~KB}$. The file format is CSV. Data are available in file Suppl. material 1.

\section{Acknowledgements}

I thank all biologists and technicians who assisted with data collection and specimen identifications.

\section{References}

- Darsie RF, Morris CD (2003) Keys to the adult females and fourth instar larvae of the mosquitoes of Florida (Diptera, Culicidae). Technical Bulletin of the Florida Mosquito Control Association 1: 1-159.

- DeMay DJ, Hribar LJ (2008) Mosquito fauna of Key Largo, Florida. Journal of the American Mosquito Control Association 24: 471-477. https://doi.org/10.2987/5768.1

- Hribar LJ (2002) Mosquito (Diptera: Culicidae) collections in the Florida Keys, Monroe County, Florida, USA. Studia Dipterologica 9: 679-691. 
- Hribar LJ (2020) Expanding basic entomological knowledge by using mosquito surveillance bycatch. Annals of the Entomological Society of America 113: 439-446.

https://doi.org/10.1093/aesa/saaa014

\section{Supplementary material}

\section{Suppl. material 1: Cross Key doi}

Authors: Lawrence J. Hribar and David J. Demay

Data type: Occurrences

Brief description: Occurrences of mosquito species (Diptera: Culicidae) on Cross Key, Monroe County, Florida, USA.

Download file $(68.37 \mathrm{~kb})$ 